10. Owen L, Laird K. The role of textiles as fomites in the healthcare environment: a review of the infection control risk. Peer J 2020;8:e9790.

11. Haley R, Culver D, White J, et al. The efficacy of infection surveillance and control programs in preventing nosocomial infections in US hospitals. Am J Epidemiol 1985;121:182-205.

12. Sencer D, Axnick D. Utilization of cost-benefit analysis in planning prevention programs. Acta Med Scand 1974;Suppl 576:123-129.

13. Klevens R, Edwards J, Richards C, et al. Estimating healthcare-associated infections and deaths in US hospitals, 2002. Public Health Rep 2007;122:160-166.

14. Zimlichman E, Henderson D, Tamir O, et al. Healthcare-associated infections, a meta-analysis of costs and financial impact on the US healthcare system. JAMA Intern Med 2013;173:2039-2046.

15. House of Commons Library Research Service. Raising standards of infection prevention and control in the NHS. House of Commons Library, No. CDP2018-0116, 23. US Parliament website. https://commonslibrary.parliament. uk/research-briefings/cdp-2018-0116/. Published May 14, 2018. Accessed April 9, 2020.

16. Fast facts on US hospitals (2015 survey). American Hospital Association website. https://www.aha.org/system/files/2018-01/fast-facts-us-hospitals2017_0.pdf. Accessed March 31, 2020.
17. Fast facts on US hospitals (2018 survey). American Hospital Association website. https://www.aha.org/system/files/2020-01/fast-facts-us-hospitals2020_0.pdf. Accessed March 31, 2020.

18. Tamarchi M. What are the odds? How Stuff Works website. https://health. howstuffworks.com/diseases-conditons/death-dying/odds-of-death.htm. Accessed May 2, 2020.

19. Laufman H, Belkin N, Meyer K. A critical review of a century's progress in surgical apparel: how far have we come? Surg Apparel 2000;191: 554-568.

20. Rutala W, Weber D. A review of single-use and reusable gowns and drapes in health care. Infect Control Hosp Epidemiol 2001;22:248-257.

21. Gruendemann B. Taking cover: single-use vs. reusable gowns and drapes. Infect Control Today 2002;6:32-34.

22. Overcash M, Griffing E, National Economic Comparisons of Reusable and Single-Use Cleanroom Textile Products. Shawnee Mission, KS: American Reusable Textile Association; 2019: 8 pp.

23. CDC/HICPAC Guidelines for environmental infection control in healthcare facilities. Centers for Disease Control and Prevention website. https://www.cdc.gov/hicpac/pdf/guidelines/eic. Published 2003, updated July, 2019. Accessed March 31, 2020.

\title{
Change in trends of hospitalizations and deaths with mention of Clostridioides difficile infection in northeastern Italy, 2008-2019
}

\author{
Stefania Bellio $M D^{1}$ (1), Ugo Fedeli $M D^{1}$, Elena Schievano $M D^{1}$ and Mario Saia MD \\ ${ }^{1}$ Azienda Zero, Veneto Region, Padua, Italy
}

To the Editor-According to a recent systematic review, the incidence of Clostridioides difficile infection (CDI, previously known as Clostridium difficile infection) decreased from 2005 to 2015 in most European countries and have stabilized in North America, possibly due to active diseases surveillance, reinforced antibiotic stewardship, and stringent infection control policies. ${ }^{1}$ Namely in England, analyses of hospital episode statistics demonstrated a peak in CDI incidence in 2006-2007 followed by a steep decline. ${ }^{2}$ Mention of CDI in death certificates followed a similar pattern. ${ }^{3}$

Nonetheless, such favorable trend does not involve all European countries. In Spain, CDI-related hospitalizations increased between 2001 and 2015, both in analyses of primary and secondary discharge diagnoses, possibly reflecting an increase in the incidence of the infection, in the severity of the cases affected, or a greater awareness of the problem by clinicians with enhanced searching for cases. ${ }^{4}$

Recent reports suggest that coronavirus disease 2019 (COVID19) prevention measures might affect the risk of $\mathrm{CDI}^{5}$; however, baseline data on recent trends in Italy are lacking. Surveillance of CDI is still not active at the national level in Italy, nor in the Veneto region (northeastern Italy, about 4,900,000 inhabitants). In the absence of laboratory-based surveillance, in a previous report analyzing hospital discharge diagnoses and causes of death data, an increase in CDI rates was demonstrated in Veneto from 2008 to $2013 .{ }^{6}$ We updated previous figures to determine whether this unfavorable trend continued in 2019.

Author for correspondence: Stefania Bellio, E-mail: stefania.bellio@azero.veneto.it Cite this article: Bellio S, et al. (2022). Change in trends of hospitalizations and deaths with mention of Clostridioides difficile infection in northeastern Italy, 2008-2019. Infection Control \& Hospital Epidemiology, 43: 1512-1513, https://doi.org/10.1017/ice.2021.317
Discharges with primary or secondary CDI diagnosis using International Classification of Diseases, Ninth Revision, Clinical Modification (ICD-9-CM) code 008.45 were extracted from the regional archive of discharge records for patients aged $\geq 1$ year in the period from January 1, 2008, to December 31, 2019. In total, 9,787 records were identified, and among them $32.7 \%$ had CDI as the primary diagnosis and $73.8 \%$ were elderly ( $\geq 75$ years). The overall rate of CDI diagnosis per 1,000 discharges was 1.6, and it increased with age, reaching its highest $(5.1 \%$ ) among the very elderly ( $\geq 85$ years). The rate increased slightly during 2008-2019, with a peak in $2015(2.5 \%$ ). The population-based rates showed an even much steeper increase with age, with 16.9 CDI diagnoses per 100,000 population and a rate of 214.2 among the very elderly. The joinpoint regression analysis highlighted a significant increase of population-based rates from 2008 to 2015 (annual percentage change [APC], 14.0; 95\% CI, 10.0-18.1; $P<.001)$ and decreases in the following years (APC, $-7.3 ; 95 \% \mathrm{CI},-14.8$ to 0.7 ; $P=.10$ ), with a peak of 25.1 per 100,000 population in 2015 . A similar trend was observed for discharges with CDI as primary diagnosis (Fig. 1).

In addition to hospitalization data, the regional mortality records were analyzed. The ICD-10 code for CDI, A047, was retrieved from records of multiple causes of death for 20082019. In total, 1,317 mortality records were identified, and $43.6 \%$ had CDI as the underlying cause of death. Most deaths (52.6\%) involved the very elderly, $84.7 \%$ were among hospitalized patients, and $10.1 \%$ were among those from long-term care facilities. The mortality rate per 100,000 population increased during this period, from 0.8 in 2008 to 2.2 in 2019 and reaching a peak of 3.7 in 2015 (Fig. 1). The rate significantly increased during 


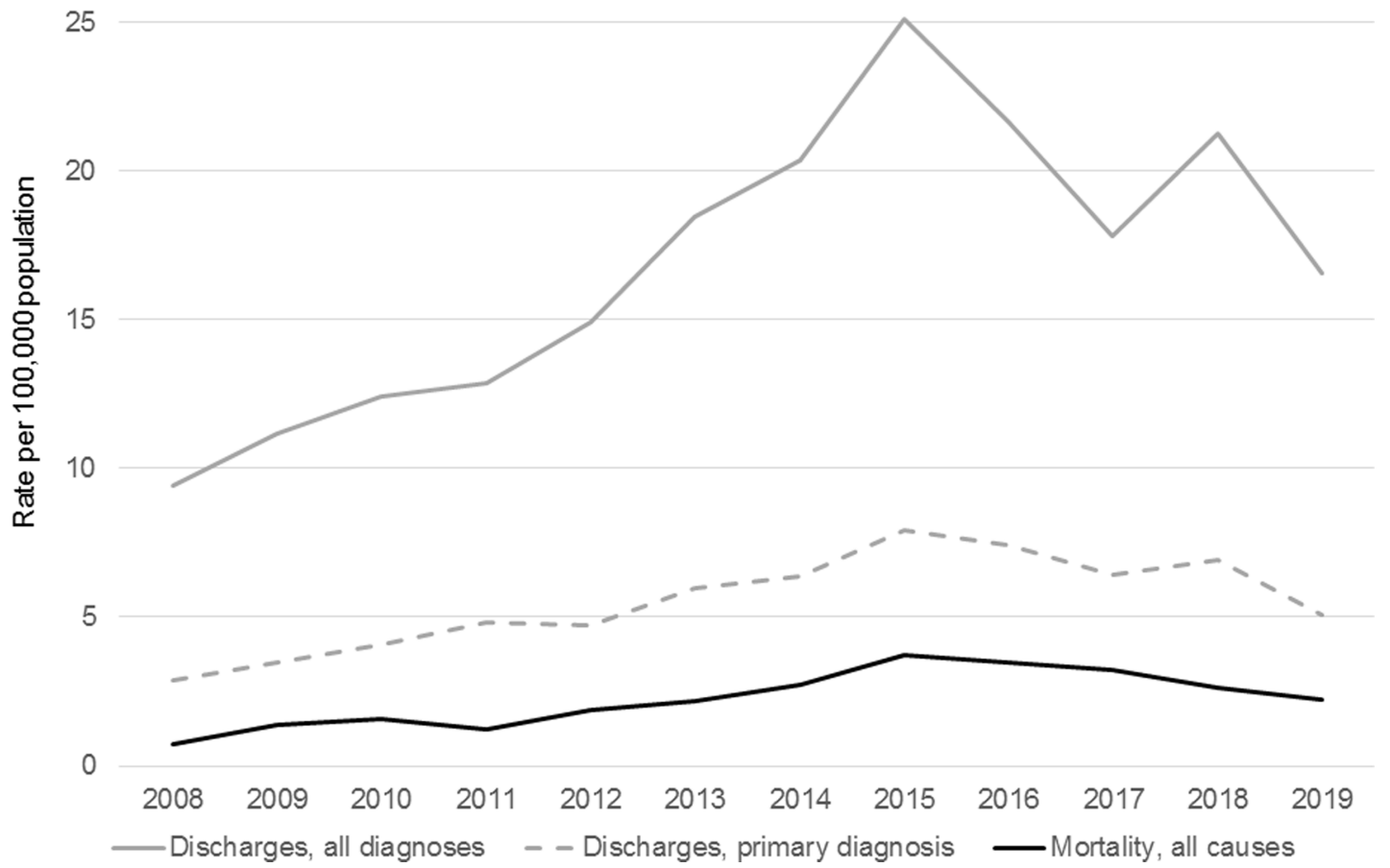

Fig. 1. Hospitalization and mortality rates related to Clostridioides difficile infection: population aged $\geq 1$ year, Veneto region (Italy), 2008-2019.

2008-2016 by $19.1 \%$ per year (95\% CI, 11.9-26.8; $P<.001)$ and decreased in the following years by $16.9 \%$ per year $(95 \% \mathrm{CI}$, -37.6 to $10.7 ; P=.20$ ).

This report shows an increasing trend of CDI from hospital discharge and mortality records from 2008 to 2015 and a decrease from 2016 to 2019, irrespective of whether analyses were carried out on primary or on all discharge diagnoses or on multiple causes of death. The reduction of CDI diagnoses can be explained by reinforced antibiotic stewardship and infection control policies or, on the contrary, by a growing rate of underdiagnosed infections, since a national or regional active disease surveillance has not yet been established. However, this specific trend was also reported in other European countries, although the reversion and reduction were recorded starting from 2004. ${ }^{1}$ Despite the decreasing trend observed in Veneto in the last few years, the peak rate of CDI diagnoses per 100,000 population in 2015 was much higher than figures reported in Spain. ${ }^{4}$

Future analyses on CDI incidence will probably present different figures because of the deep changes in infection control policies following the COVID-19 pandemic. Therefore, this report also represents an important baseline for future comparisons to assess the real impact of COVID-19 prevention measures on the risk of CDI.
Financial support. No financial support was provided relevant to this article.

Conflicts of interest. All authors report no conflicts of interest relevant to this article.

\section{References}

1. Ho J, Wong SH, Doddangoudar VC, Boost MV, Tse G, Ip M. Regional differences in temporal incidence of Clostridium difficile infection: a systematic review and meta-analysis. Am J Infect Control 2020;48:89-94.

2. Jen MH, Saxena S, Bottle A, Pollok R, Holmes A, Aylin P. Assessment of administrative data for evaluating the shifting acquisition of Clostridium difficile infection in England. J Hosp Infect 2012;80:229-237.

3. Cole A. MRSA and C difficile deaths continue to fall in England and Wales. BMJ 2013;347:f5278.

4. Esteban-Vasallo MD, de Miguel-Díez J, López-de-Andrés A, HernándezBarrera V, Jiménez-García R. Clostridium difficile-related hospitalizations and risk factors for in-hospital mortality in Spain between 2001 and 2015. $J$ Hosp Infect 2019;102:148-156.

5. Bentivegna E, Alessio G, Spuntarelli V, et al. Impact of COVID-19 prevention measures on risk of healthcare-associated Clostridium difficile infection. Am J Infect Control 2020;49:640-642.

6. Fedeli U, Schievano E, Pellizzer G. Increasing numbers of hospitalizations and deaths with mention of Clostridium difficile infection, northeastern Italy, 2008-2013. Clin Microbiol Infect 2015;21:e63-e64. 